\title{
LAS SANCIONES CONTEMPLADAS POR EL INCUMPLIMIENTO DE LOS ACUERDOS DEL COMERCIO INTERNACIONAL \\ En particular el régimen de sanciones establecidas en el Marco de la Organización Mundial de Comercio
}

\author{
JAime GALlegos ZúNigA* \\ Universidad de Chile
}

\begin{abstract}
RESUMEN: El presente estudio se detiene en el mecanismo de solución de controversias internacionales entre miembros de la Organización Mundial de Comercio (OMC), comparando este sistema, con los mecanismos de solución de controversias del Tratado de Libre Comercio suscrito entre Chile y Estados Unidos; el Acuerdo de Asociación Estratégica entre Chile y la Unión Europea y el Protocolo de Olivos, que regula estas materias en el seno del Mercosur. Este trabajo busca exponer las eventuales sanciones a que queda expuesto un Estado infractor de los compromisos internacionales asumidos, en virtud de estos acuerdos, tomando especial consideración en la naturaleza interestatal de estos conflictos. Tal naturaleza interestatal nos obliga a ponderar estas controversias con parámetros distintos a los dados para una controversia interna dentro de un Estado en particular, ello, principalmente porque no existe un poder de imperio supranacional que coarte efectivamente al Estado infractor a desarrollar una conducta que no vulnere lo convenido. Pese a lo anterior, del examen de los diferentes casos expuestos podemos constatar que -en general- los países han dado cumplimiento a las obligaciones internacionales contraídas, dotando de certeza a los acuerdos aludidos.
\end{abstract}

Palabras clave: Solución de Controversias, Organización Mundial de Comercio (OMC), Comercio Internacional, Retorsión.

ABSTRACT: This study focuses con the mechanism for solving international conflict amongst members of the World Trade Organization (WTO), in contrast to the mechanism established in the Free Trade Agreement between Chile and the United States; the Agreement of Strategic Alliance between Chile and the European Union and the Olivos Protocol, which regulates such matters amongst members of MERCOSUR. This study aims to showcase the potential sanctions that may fall upon a State that violates international commitments regulated by said treaties, giving particular consideration to their multinational nature. This particular characteristic forces us to analyze the issue with different parameters than those used for internal conflict within a given State, mainly due to the lack of a supranational entity capable of effectively enforcing multinational agreements. In spite of the above, after examining the cases that compose this study it can be said that -in generalstates have complied with the internationl obligations the have assumed, thus ensuring the agreements we have mentioned.

Key words: Solution of international disputes, World Trade Organization (WTO), International Trade, Retaliation.

Ante un eventual nuevo conflicto que involucraría a nuestro país como reclamante, por una supuesta violación de los Acuerdos de la Organización Mundial de Comercio (OMC), relativos a subsidios en materia forestal que Estados Unidos entrega a sus produc-

\footnotetext{
* Abogado, Profesor del Departamento de Derecho Económico de la Facultad de Derecho de la Universidad de Chile. Magíster (c) en Derecho de los Negocios Internacionales de la Universidad Complutense de Madrid, España.
} 
tores locales ${ }^{1}$, estimamos oportuno detenernos y exponer el sistema de solución de controversias contemplado por este organismo multilateral de comercio internacional, y en particular las sanciones a que da lugar la constatación de una vulneración a las obligaciones contraídas, que conduzcan a una anulación o menoscabo para los productores y/o exportadores de otro Estado miembro.

La OMC tiene sus remotos orígenes en el GATT (General Agreement on Tariffs and Trade, Acuerdo General sobre Aranceles Aduaneros y Comercio) de 1947, en aquella ocasión se intentó crear una nueva estructura económica internacional de carácter multilateral ${ }^{2}$, que fuese capaz de evitar caer en las situaciones económicas y sociales que condujeron -entre otros factores- a la Segunda Guerra Mundial, regulando el comercio internacional, estableciendo nuevos sistemas de financiamiento para la reconstrucción de las naciones y dictando pautas en materia de política monetaria y problemas en la balanza de pagos.

En esta línea, como fruto de la Conferencia de Bretton Woods, celebrada en New Hampshire, EE.UU. en 1944, se creó el Fondo Monetario Internacional y el Banco Internacional de Reconstrucción y Fomento, además se intentó crear la Organización Internacional de Comercio. Sin embargo, esta última entidad no pudo nacer, ya que no contó con el respaldo del Senado de los Estados Unidos de América, en la suscripción de la Carta de La Habana (que buscaba la creación de esta Organización), pese a que esta iniciativa había sido impulsada por el Ejecutivo de este país ${ }^{3}$. El hecho de que Estados Unidos no suscribiera este acuerdo provocó que otros Estados tampoco adhirieran a este ambicioso proyecto.

"Terminada la guerra, nació la idea de regularizar la actividad comercial por medio de una legislación mundial, tal como se había planteado en lo financiero y en el campo de lo monetario internacional. Por ello, se convocó a una Conferencia en La Habana (1948). Se elaboró un documento, proyecto orgánico de una gran institución mundial de comercio, elaborado por ECOSOC ${ }^{4}$. Se trataba de un documento amplio, excesivamente ambicioso, y que, por tales razones, sembró desconfianza entre los países claves, los que le negaron su aprobación. En él se establecía una institucionalización completa para el comercio mundial. Fue precisamente esta ambición y este utopismo los que llevaron al fracaso de la iniciativa" 5 .

En todo caso, el que no se haya podido formar un organismo internacional propiamente tal, que respaldase y dotare de una estructura permanente al comercio internacional de mercaderías, no fue óbice para que el GATT, que sí fue respaldado por un número

\footnotetext{
1 "FORESTALES de EE.UU., presionan para seguir recibiendo subsidios". El Mercurio, Santiago, Chile, 2 de julio, 2009. B- 5.

2 BARre, Raymond. Economía Política 2, .7a ed.- (traducción de José Ignacio García Lomas), Barcelona: Editorial Ariel, 1958, p. 634- 644. ; TAMAmes, Ramón. HuerTA, Begoña. Estructura Económica Internacional, -19a ed.- Madrid: Alianza Editorial, 1999, p. 57-177; ElLSWORTH y CLARK. Comercio Internacional -3a edición en español- México DF: Fondo de Cultura Económica, 1978, p.503.; SALDAN̄A PÉREZ, Juan Manuel. Comercio internacional. Régimen Jurídico Económico. México DF: Editorial Porrúa, 2008. p. 9-21.

3 Tamames, Ramón. Huerta, Begoña, op. cit. (n. 2), p. 158.

${ }^{4}$ Consejo Económico y Social de Naciones Unidas.

${ }^{5}$ Aimone Gibson, Enrique. Derecho Económico Internacional. Valparaíso: Ediciones Universitarias de Valparaíso, 1980, p. 97.
} 
significante de países $^{6}$, sirviese como el marco normativo para el desarrollo progresivo de estas actividades económicas.

El paulatino crecimiento del comercio internacional condujo a que el texto primitivo del GATT fuese insuficiente, lo que condujo a que este sufriera una serie de modificaciones, que fueron abordadas a través de las Rondas ${ }^{7}$, que con cierta periodicidad fueron tratando las nacientes temáticas surgidas del intercambio interfronterizo de mercaderías, como el dumping $^{8}$, salvaguardias ${ }^{9}$, beneficios especiales a países en vías de desarrollo ${ }^{10}$, entre otros.

La Ronda más trascendente, dentro de esta línea de trasformaciones del GATT de 1947, fue la Ronda de Uruguay iniciada en 1986 en la ciudad de Punta del Este, no solo por la enorme variedad de temáticas en ella abordada, sino que también porque fruto de esta ronda se alcanzó el Acuerdo de Marrakech de 1994, que además de perfeccionar la normativa referente al comercio de mercaderías, incorporó acuerdos que regulan el comercio de servicios y los derechos de propiedad intelectual relativos al comercio ${ }^{11}$, ampliando enormemente el campo de acción y los supuestos regulados, contemplando además un marco más acorde con las nuevas necesidades y los desarrollos tecnológicos.

Por otra parte, a partir del 1 de enero de 1995, se dio vida a un nuevo sujeto de Derecho Internacional, la Organización Mundial de Comercio, con una estructura y un organigrama, necesarios para poder abordar de manera seria el complejo mundo del intercambio internacional de bienes y servicios. Se estimó que era necesaria la constitución de una organización internacional para poder llevar a cabo la labor de ser foro permanente de

\footnotetext{
${ }^{6}$ Entre los países que suscribieron este Acuerdo se encuentran Australia, Bélgica, Brasil, Birmania, Canadá, Ceylán, Cuba, Checoslovaquia, Chile, Taiwán, Estados Unidos, Francia, Gran Bretaña, Holanda, India, Líbano, Luxemburgo, Noruega, Nueva Zelanda, Pakistán, Rhodesia, Siria y la Unión Sudafricana.

${ }^{7}$ MaC LEAn, Roberto. Derecho de Comercio Internacional, Nuevas Tendencias. Lima: Centro de Investigación y Capacitación, Editorial ITAL Perú S.A., 1980. p. 15; TAMAMES, Ramón y HUERTA, Begoña. op. cit. (n. 2) pp. 161-175.

${ }^{8}$ Podemos definir -a grandes rasgos- el dumping como el comportamiento de un exportador consistente en la venta en un mercado externo a un precio más bajo que su valor normal, entendiendo por tal, el precio al que vende la misma mercadería o una similar en el mercado interno con la finalidad -si esta conducta es ilegítima- de adquirir una posición dominante en un determinado mercado, para que una vez alcanzado este estatus pueda a su arbitrio modificar libremente los precios de las mercaderías respectivas. Ver. Sierralta Ríos, Aníbal. Contratos de Comercio Internacional -4º ed.- Lima: Pontificia Universidad Católica del Perú, Fondo Editorial, 2004. pp. 72-75.; SAldaÑa PÉREZ, Juan Manuel. Comercio internacional. Régimen Jurídico Económico. op. cit. (n. 2), pp. 99-408; BASALDÚA, Ricardo Javier. La Organización Mundial del Comercio y la regulación del Comercio Internacional. Argentina: LexisNexis S.A., 2007. pp.281-305.; FrATALOCCHI y Zunino. El Comercio Internacional de Mercaderías. Su regulación en la Organización Mundial de Comercio. Buenos Aires: Osmar D. Buyatti Librería Editorial, 1997. p. 95- 180.; MARZORATI, Osvaldo J. Derecho de los Negocios Internacionales. 2a edición actualizada y ampliada- Buenos Aires: Editorial Astrea, 1997. pp. 163-168.

9 Podemos definir -a grandes rasgos- las salvaguardias como aquella medida esencialmente temporal que puede adoptar un Estado, tendiente a limitar restricción el ingreso de mercaderías importadas, en atención al daño grave o la amenaza de que este se verificase en su industria nacional, con ocasión de aumento imprevisto de las mercaderías foráneas. Ver. SALdAÑA PéreZ, Juan Manuel. op. cit. (n. 2), p. 409-476.; BASALdúA, Ricardo Javier, op. cit. (n. 8), p.331- 345.; Fratalocchi Y Zunino. op. cit. (n. 8), p.293-332.; MARZORATI, Osvaldo J, op. cit. (n. 8), pp. 160-163.

${ }^{10}$ Los países en vías de desarrollo cuentan con mayor flexibilidad con respecto a las obligaciones que le impone el sistema multilateral de comercio, lo que se manifiesta a través del sistema generalizado de preferencias arancelarias y otras exenciones y mayores plazos ante determinadas resoluciones o ejecución de acuerdos de la OMC. Ver. SALDAÑa PÉREZ, Juan Manuel, op. cit. (n. 2), p. 39.; BASAldúA, Ricardo Javier. op. cit. (n. 8), p. 163-172.; TAMAMES, Ramón y HuERTA, Begoña. op. cit. (n. 2), pp. 164 y 185.

11 Respecto a la presión ejercida por los Estados Unidos tendientes a la incorporación de acuerdos que protegieran los derechos de propiedad intelectual relativos al comercio ver TAMAMES, Ramón y HUERTA, Begoña, op. cit. (n. 2), p. 174.
} 
negociaciones, que permitiese la confluencia de las distintas naciones, el examen de las políticas comerciales de los miembros, que fuere el punto de encuentro donde se discutan las prácticas atentatorias contra el libre comercio, se evalúen las reducciones de aranceles, entre otros puntos.

Con todo, las ideas someramente esbozadas no fueron las únicas innovaciones que trajo consigo la Ronda de Uruguay, ya que otro cambio sustancial respecto a la normativa contenida en el GATT de 1947 dice relación con el sistema de solución de controversias ${ }^{12}$, puesto que se llegó a la convicción que el sistema hasta entonces vigente adolecía de una serie de falencias, que lo hacía en la práctica poco eficaz.

Dentro de las falencias y deficiencias que presentaba el mecanismo del GATT se ha señalado: "El GATT tenía una serie de defectos tales como su aplicación de carácter provisional; la carencia de una estructura institucional (por lo que solo había Estados "contratantes" y no Estados miembros); limitaciones en su aplicación por los llamados "Grandfather's Rights", o derechos adquiridos en virtud de los cuales las normas del GATT estaban subordinadas a la legislación interna de cada país preexistente al Acuerdo General; imposibilidad de reforma dado que debía procederse en todo con la unanimidad de los Estados Contratantes; falta de una clara relación con la legislación doméstica en cada uno de los Estados Contratantes; accesión y membresía de las ex colonias de los Estados Contratantes sin concesiones de su parte; desarrollo inorgánico de tratados laterales específicos entre algunos países contratantes, los que tenían su propio mecanismo de solución de controversias y respecto de los cuales no existía claridad sobre su supremacía o subordinación respecto del Acuerdo General, etc. Quizás el mayor de los defectos radicaba en la ineficacia del Mecanismo de Solución de Controversias dado que en definitiva la aplicación de las decisiones de los paneles arbitrales llamados a solucionar una controversia pasaba necesariamente por la aprobación de todos los Estados Contratantes, incluida la del país perdedor" ${ }^{13}$.

Hoy la relevancia que se le da, dentro de la OMC, al sistema de solución de controversias queda de manifiesto al revisar lo señalado por el artículo 3.2 del cuerpo normativo que regula esta materia (ESD), que dispone:

"El sistema de solución de diferencias de la OMC es un elemento esencial para aportar seguridad y previsibilidad al sistema multilateral de comercio. Los Miembros reconocen que ese sistema sirve para preservar los derechos y obligaciones de los Miembros en el marco de los acuerdos abarcados y para aclarar las disposiciones vigentes de dichos acuerdos de conformidad con las normas usuales de interpretación del derecho internacional público. Las recomendaciones y resoluciones del

\footnotetext{
12 Cadena Afanador, Walter. La nueva Lex Mercatoria. La transnacionalización del Derecho. Bogotá: Centro de Investigaciones Socio Jurídicas, Facultad de Derecho, Universidad Libre de Colombia, 2004, p. 160.

13 Arteaga Echeverría, Ignacio. Procedimiento de solución de controversias en la Organización Mundial de Comercio. En: Gaceta Jurídica, No 261, 2002, LexisNexis, Santiago, p. 8.; OMC. Manual sobre sistema de solución de diferencias de la $O M C$, Éditions Yvon Blais, Quebec, 2004. p. 16-18; Basaldúa a este respecto señala: "El denominado sistema de solución de diferendos del GATT fue objeto de críticas fundadas precisamente por su lentitud, porque permitía el bloqueo por parte del Estado acusado y porque no aseguraba la ejecutividad de lo recomendado por los grupos de trabajo o de expertos convocados a pronunciarse sobre el conflicto planteado entre las partes contratantes. También se observó la diversificación o fragmentación excesiva de las reglas aplicables, que resultaba de la coexistencia de diferentes procedimientos para solucionar los diferendos previstos en los distintos acuerdos”, BASALDÚA, Ricardo Javier, op. cit. (n. 8), p. 532.
} 
OSD no pueden entrañar el aumento o la reducción de los derechos y obligaciones establecidos en los acuerdos abarcados".

Tal ha sido el impacto y relevancia de este sistema, que un reconocido autor nacional, como Juan Guillermo Espinosa sostiene que el Procedimiento de Solución de Diferencias de la $\mathrm{OMC}$ es, sin lugar a dudas, la contribución más particular de la OMC a la estabilidad del comercio mundial ${ }^{14}$. Otros han sido más enfáticos aún, señalando que existe consenso que el procedimiento de solución de diferencias de la $\mathrm{OMC}$ es el más eficiente que existe en el mundo ${ }^{15}$.

Se estructuró un sistema de solución de controversias interestatales ${ }^{16}$, el Entendimiento relativo a las normas y procedimientos por los que se rige la Solución de Diferencias (ESD), que figura en el Anexo II del Acuerdo sobre la OMC, tendiente a que sean las propias partes, según se desprende de lo establecido en el artículo 3.7 de este acuerdo, que nos dice: "El objetivo del mecanismo de solución de diferencias es hallar una solución positiva a las diferencias. Se debe dar siempre preferencia a una solución mutuamente aceptable para las partes en la diferencia y que esté en conformidad con los acuerdos abarcados". Para ello, en primer término se fijó -como requisito previo- la necesidad de que se entablen consultas $^{17}$, entre las partes, buscando que a través de estas negociaciones se pueda resolver la diferencia.

${ }^{14}$ Espinoza Carmona, Juan Guillermo. De Doha a México. La actual ronda de negociaciones multilaterales en la OMC y la participación de los paises de América Latina y el Caribe en este debate. Santiago: Academia Diplomática de Chile Andrés Bello, 2003, pp. 71-72.

15 BigGS, Gonzalo. "El mecanismo de solución de controversias en la Organización Mundial de Comercio (OMC)". En Jornadas de Derecho Internacional: 29 de noviembre a 2 de diciembre de 2004. Santiago, Organización de Estados Americanos y Sociedad Chilena de Derecho Internacional, 2005, p. 120.

${ }^{16}$ BASALDÚA, Ricardo Javier. op. cit. (n. 8), p. 535. Canal Forgues (citado por este autor) refiriéndose al carácter interestatal del sistema de solución e controversias de la OMC nos dice: "Es en efecto difícil sostener que el contencioso del comercio internacional es por naturaleza interestatal, puesto que es fundamentalmente el hecho de comerciantes, que ya no son hoy en día los Estados sino los operadores económicos privados. Buen número de las ventajas que se reputan derivar para los Miembros de la aceptación de los acuerdos de la OMC dependen en realidad de la actividad de los agentes económicos sobre los mercados nacionales y mundiales. Uno de los principales objetivos de la OMC, indicó, por otra parte el Grupo Especial en el asunto Estados Unidos, secc. 301, es el de 'crear las condiciones de mercado que permitirán a esta actividad individual prosperar'. Es también la razón por la cual, a diferencia de los mecanismos de puesta en juego de la responsabilidad internacional de los Estados, una legislación nacional de un Miembro que establece, por ejemplo, una discriminación, es susceptible de ser considerada ella misma como una violación al Art. III del GATT, por el simple hecho de su existencia e independientemente de su aplicación a casos particulares, puesto que puede tener por efecto retrasar las actividades de los agentes económicos modificando, por ejemplo, las posibilidades de concurrencia relativa entre productos nacionales e importados por el hecho de un cambio de las habitudes de los consumidores". Destaca que "En el asunto que enfrentó en 1989 al Japón y los Estados Unidos con relación a las películas y papeles fotográficos, lo que estaba subyacente, en realidad, era un litigio entre dos multinacionales, Fuji y Kodak". Por otra parte, no debemos dejar de tener presente que algunos miembros de la OMC han dictado leyes que permiten a los particulares elevar peticiones a sus gobiernos para que estos inicien una diferencia en la OMC, así ocurre con la Ley de Comercio de Estados Unidos (art. 301 y siguientes) y el Reglamento sobre los Obstáculos Comerciales de las Comunidades Europeas. Además, se admite como miembros de la OMC no solo a Estados nación propiamente tales, sino que también se admiten como miembros a territorios aduaneros, como ocurre con Hong Kong y Taiwán. Sin embargo, dado que en la generalidad de los casos son Estados los involucrados en estos conflictos, en el desarrollo de esta exposición se empleará usualmente la expresión "Estado" o "país" para referirnos a un miembro de la OMC, no obstante no sean estos los únicos sujetos legitimados como miembro de la OMC.

${ }_{17}$ Un caso representativo del acuerdo entre las partes, como modo de solucionar conflictos se dio en la Diferencia DS 232 (Medidas que afectan la importación de fósforos) que enfrentó a Chile -como reclamante- y a México -como reclamadoel año 2001 . 
"En lo que se refiere a la etapa de consultas, si bien no está establecida en las normas la función que debe cumplir el OSD, entendemos que del párrafo 4 del artículo 4 se desprende que el OSD debe notificar de la realización de consultas a todos los miembros de la organización internacional. La finalidad de la notificación al OSD en consultas es salvaguardar los intereses de las demás partes ${ }^{18}$ del sistema multilateral que no conozcan la diferencia, pero que podrían tener interés en participar" ${ }^{\prime 9}$.

Durante esta etapa se contempla la posibilidad del que el Director General de la OMC aporte con sus buenos oficios, conciliación o mediación para la solución del conflicto (art. 5.6. ESD).

Si agotada esta primera fase de acercamiento entre las partes, no ha sido posible solucionar el conflicto, se establece una serie de mecanismos, dentro de plazos estableci$\operatorname{dos}^{20}$, para que se resuelva si la conducta impugnada por un Estado miembro importa una

En mayo del año 2001 Chile solicitó la celebración de consultas con México, a raíz de normativa de aquel país que implicaba un obstáculo innecesario al acceso y comercialización de fósforos, en atención a que dichos productos quedaban sujetos al control de la Secretaría de Defensa de la nación azteca, que a través de una serie de requisitos imponía diferentes obstáculos, que a juicio de Chile eran atentatorios al Acuerdo sobre Obstáculos Técnicos al Comercio y otros acuerdos de la OMC.

Dadas las negociaciones que se sostuvieron entre los Estados involucrados se llegó a un acuerdo satisfactorio para los intereses del reclamante. En mérito a ello, en febrero del año 2004 Chile comunicó al Órgano de Solución de Diferencias su intención de retirar la solicitud de consultas, y poner así término a la diferencia.

Otro caso emblemático, en que también se solucionó el conflicto en la fase de consultas tuvo lugar en la Diferencia DS 326 (Medida de salvaguardia relativa al salmón), en este caso Chile -en abril del año 2005-impugnó el Reglamento No 206 de 2005 de las Comunidades Europeas en que establecía una salvaguardia definitiva al salmón de piscifactoría, por estimar que tal decisión era contraria a las normas del GATT y el Acuerdo de Salvaguardias de la OMC, en atención a que -a su juicio- no se daban los supuestos que la hacen procedente.

En mayo del año 2005 Chile notificó a la OSD que retiraba formalmente su reclamación, toda vez que, en mérito a las negociaciones sostenidas, la salvaguardia objetada había sido suprimida por las Comunidades Europeas.

18 Sobre este punto, el Art. 9 del ESD regula los casos en que haya pluralidad de partes reclamantes respecto a un mismo asunto. En este caso se podrá establecer un Grupo Especial único que deberá ponderar los derechos de todas las partes involucradas.

En el evento en que se forme más de un Grupo Especial para que se conozca de un mismo asunto, se buscará -en la medida de lo posible- que actúen las mismas personas como integrantes de los Grupos Especiales, como mecanismo para alcanzar uniformidad en las soluciones alcanzadas.

Debemos tener presente que para que un tercer Estado miembro pueda intervenir en una Diferencia es necesario que tenga un interés sustancial en el asunto sometido al conocimiento del Grupo Especial, y haber notificado tal situación al OSD (art. 10.2 del ESD).

19 Pierola Castro, Fernando. Solución de diferencias en la Organización Mundial de Comercio. Lima: Instituto de Estudios Internacionales, Pontifica Universidad Católica del Perú, Editorial DESA, 2002, p. 73. Respecto a la necesidad de consultas como paso previo para la formación de un Grupo Especial que conozca la diferencia se puede ver. CRUZ Miramontes, Rodolfo. Las Controversias comerciales en el marco de la Organización Mundial de Comercio (OMC), en: Anuario Hispano-Luso-Americano de Derecho Internacional, No 16, Instituto Hispano-Luso-Americano de Derecho Internacional, Madrid, 2003, pp. 325-341.

${ }^{20}$ Un Estado miembro solicita por escrito y fundadamente, mediante la respectiva notificación al OSD y a los Comités permanentes, según la materia a tratar, que se entablen consultas ante la anulación o menoscabo de un derecho conferido en virtud de los Acuerdos de la OMC. Ante ello, el Estado impugnado cuenta con un plazo de diez días para responder este requerimiento, y un plazo de treinta días para entablar efectivamente las consultas solicitadas desde la fecha de recepción de aquella solicitud (diez días si las mercaderías objeto de la disputa son perecederas).

Si las consultas no permiten arribar a una solución de la diferencia al cabo de sesenta días (veinte días para mercaderías perecederas), el reclamante puede pedir fundadamente la formación de un Grupo Especial para que sea este, como un ente ajeno a las partes, el que heterónomamente resuelva el conflicto.

En el caso de que el Estado impugnado no comparezca a entablar consultas, caduca el plazo de duración de estas de los sesenta días, y de inmediato el Estado reclamante puede solicitar la formación del Grupo Especial. 
anulación o menoscabo de cualquiera de los acuerdos vinculantes a los países miembros de la OMC. El hecho de que se verifique que hay una medida, práctica u omisión ${ }^{21}$ atentatoria contra los compromisos y acuerdos de la OMC hace presumir el perjuicio o menoscabo para el Estado miembro acusador, lo que invierte la carga de la prueba en esta materia (art. 3.8 ESD) ${ }^{22}$, ya que no es deber del Estado reclamante el demostrar el perjuicio que tal conducta está provocando en su economía, el solo incumplimiento de las normas de la OMC hace que el menoscabo se presuma.

Esta segunda fase se inicia con la formación de un Grupo Especial (o panel), grupo de expertos, formado en principio por tres integrantes, quienes serán los encargados de conocer el

Una vez solicitada la formación de un Grupo Especial, el OSD cuenta con un plazo de cuarenta y cinco días para la designación de un Grupo Especial ad hoc que resuelva la contienda.

Una vez constituido el Grupo Especial, este debe preparar un calendario de trabajo -para que las partes presenten sus comunicaciones y se lleven a cabo las audiencias respectivas-, tomando en consideración de que tiene un término de seis meses para pronunciarse (tres meses en caso de mercancías perecederas). Debemos tener presente, en todo caso, durante el curso de los seis meses el Grupo Especial deberá evacuar un Informe Provisional, el que puede ser objeto de observaciones, comentarios y reparos por las partes.

Una vez concluida la fase de reexamen de los antecedentes, el Grupo Especial cuenta con un plazo de dos semanas para emitir su Informe Definitivo al OSD, el que contendrá las constataciones y conclusiones de fondo de la diferencia con las respectivas recomendaciones a seguir.

Una vez recibido el Informe del Grupo Especial, el OSD cuenta con un plazo de sesenta días para adoptar la resolución definitiva, siguiendo la regla del consenso negativo. En el evento que la parte perdedora decida apelar dentro de dicho lapso, el OSD no se pronunciará respecto del informe del Grupo Especial.

Evacuado el Informe Definitivo del Grupo Especial, como señalábamos, las partes cuentan con un plazo de sesenta días para deducir un recurso de apelación que se limite a cuestiones de Derecho. Deducido este recurso el asunto queda sometido al conocimiento de tres integrantes del Órgano Permanente de Apelación, los que cuentan con un plazo de sesenta días (que en ningún caso puede prolongarse por más de noventa días) para finalizar su examen.

Luego, dentro de un lapso de treinta días desde la recepción del Informe (del Órgano de Apelación) el OSD debe adoptar ese informe, a menos que la totalidad de los miembros lo rechace (consenso negativo), dirigiendo una recomendación y solución para poner término a la anulación o menoscabo impugnada.

En referencia a estos plazos se ha señalado (OMC. "Manual sobre sistema de solución de diferencias de la OMC", OMC, Québec, 2004, p. 8): "Estos plazos pueden parecer todavía largos, considerando el tiempo necesario para la aplicación después de adoptada la resolución. Además, el reclamante puede seguir sufriendo daños económicos resultantes de la medida impugnada durante toda la tramitación de la diferencia, e incluso, después de ganar su causa, no recibir ninguna compensación por el daño sufrido antes de la fecha fijada al demandado para la aplicación de las resoluciones y recomendaciones.

Sin embargo, debe tenerse en cuenta que las diferencias en la OMC suelen ser muy complejas desde el punto de vista fáctico y jurídico. Por lo general las partes presentan una considerable cantidad de datos y documentos relacionados con la medida impugnada, y aducen argumentos jurídicos muy detallados. Las partes necesitan tiempo para preparar estos argumentos fácticos y jurídicos y responder a los argumentos de la parte contraria. El grupo especial (y el Órgano de Apelación) al que se asigna la cuestión necesita considerar todas las pruebas y argumentos, posiblemente escuchar a expertos, y corroborar sus conclusiones con un razonamiento pormenorizado. Teniendo todo esto en cuenta puede decirse que el sistema de solución de diferencias de la OMC funciona con bastante rapidez y, en todo caso, mucho más deprisa que un gran número de sistemas judiciales nacionales o internacionales".

${ }^{21}$ Si bien en la mayoría de los casos lo que se impugnará será una conducta positiva de un Estado miembro, como puede ser: la dictación de determinada ley, decreto o resolución, la imposición de ciertos requisitos por Aduanas o servicios sanitarios, entre muchas otras, debemos también tener presente que el Acuerdo sobre los aspectos de los derechos de Propiedad Intelectual relacionado con el Comercio (ADPIC) impone a los signatarios conductas positivas a desarrollar, por lo que bien podría alegarse la omisión en la ejecución de tal compromiso internacional asumido.

22 Art. 3.8 del ESD: "En los casos de incumplimiento de las obligaciones contraídas en virtud de un acuerdo abarcado, se presume que la medida constituye un caso de anulación o menoscabo. Esto significa que normalmente existe la presunción de que toda trasgresión de las normas tiene efectos desfavorables para otros Miembros que sean partes en el acuerdo abarcado, y en tal caso corresponderá al Miembro contra el que se haya presentado la reclamación refutar la acusación”. Ver. Arteaga Echeverría, Ignacio. op. cit. (n. 13), p. 12.; Piérola Castro, Fernando, op. cit. (n. 19), pp. 61-62. 
conflicto y buscar las bases de arreglo para él23. Dentro de este procedimiento se establecieron una serie de plazos para la presentación de las partes y las impugnaciones y observaciones que se les pueda hacer, orientados siempre, como ya señalamos, a que las propias partes alcancen un acuerdo y soluciones la discrepancia ${ }^{24}$, en mérito a lo señalado en el artículo 11 del ESD: “(...) Los grupos especiales deberán consultar regularmente a las partes en la diferencia y darles oportunidad adecuada de llegar a una solución mutuamente satisfactoria” 25 .

${ }^{23}$ Esta materia se encuentra regulada en los artículos 6, 7 y 8 del ESD. El artículo 6 se refiere a la solicitud de establecer un Grupo Especial, la que deberá formularse por escrito, fundando debidamente las aseveraciones. Tal solicitud podrá declararse como admisible, siempre y cuando se acredite que la fase de consultas se encuentra agotada, por no haber podido alcanzar un arreglo, dentro de los plazos contemplados.

Luego, el artículo 7 se refiere a la competencia del Grupo Especial, que se limitará a examinar, a la luz de los Acuerdos de la OMC invocados por las partes, el asunto en disputa. En base a ello deberá formular las conclusiones a la que arribe y -eventualmente- las recomendaciones a adoptar, tendientes a restablecer el imperio de los acuerdos violentados. El artículo 8, por su parte, se refiere a la composición de los Grupos Especiales, señalando que estos estarán formados por personas muy competentes, funcionarios gubernamentales o no, y en general, personas con reconocidos conocimientos en materia de comercio internacional, siempre y cuando no sean nacionales de unos de los Estados miembros en disputa, salvo que por acuerdo entre las partes se admita esta opción.

Para facilitar la elección de los miembros del Grupo Especial ad hoc que se establecerá para conocer de la controversia la Secretaría de la OMC mantendrá una lista que contenga las personas que reúnan las cualidades indicadas.

Los grupos especiales estarán formados por tres integrantes, a menos que, dentro de los 10 días siguientes al establecimiento del grupo especial, las partes en la diferencia convengan en que sus integrantes sean cinco.

${ }^{24}$ El sistema del ESD, que da un fuerte rol a las negociaciones entre las partes, es un producto intermedio entre las ideas formuladas por las dos grandes potencias negociadoras del sistema multilateral de comercio, Europa y Estados Unidos, la primera tiende a asignar un fuerte rol a las negociaciones diplomáticas para resolver una diferencia, mientras que Estados Unidos tiende a preferir soluciones más legalistas, con procedimientos objetivos y preestablecidos (GREEnWALD, Joseph. "Solución de Controversias en la OMC", en: Foro Internacional, Volumen XLI, Número 2, Colegio de México, Ciudad de México, 2001. p. 272).

25 A este expediente se llegó en la Diferencia DS14 (Denominación Comercial de los Moluscos de Género Pectinidae) que enfrentó a Chile -como reclamante- con la Comunidad Europea -como reclamado- entre 1995 y 1996.

En este caso Chile impugnaba una decisión del gobierno francés que clasificaba los moluscos Pectinidae, asignándoles algunas características que iban en detrimento de la posición de mercado de las mercaderías chilenas. En mérito a ello Chile sostuvo que existía una violación al Acuerdo sobre Obstáculos Técnicos al Comercio.

En septiembre de 1995 Chile solicitó la conformación de un Grupo Especial, en atención a que la fase de consultas previas no arribaron a buen puerto.

Sin embargo, durante el desarrollo de funciones del Grupo Especial su actuar fue suspendido, en atención a que las partes mantuvieron negociaciones tendientes a encontrar una solución mutuamente acordada. Precisamente, en julio de 1996 las partes comunicaron al OSD que se había alcanzado un acuerdo, por lo que la labor del Grupo Especial carecía de objeto. Otro ejemplo, lo podemos observar en la Diferencia DS 227 (Tributación aplicada a los cigarrillos) que enfrentó a Chile -como reclamante- con el Perú -como reclamado- el año 2001. En este conflicto Chile impugnó un Decreto Supremo dictado por el Perú, en virtud del cual se establecía una tasa impositiva a los cigarrillos en conformidad a la procedencia de estos.

En este caso, al no satisfacerse la pretensión chilena mediante las consultas, se requirió el nombramiento de un Grupo Especial. Sin embargo, al poco andar Chile comunicó a la OMC que la diferencia había sido superada, en atención a que el Perú había modificado el Decreto Supremo impugnado, con lo que no tenía sentido que el Grupo Especial continuase conociendo del asunto.

Un tercer conflicto que también enfrentó a Chile y Perú, y del mismo modo fue resuelto mediante acuerdo entre las partes, no obstante se haya solicitado previamente la conformación de un Grupo Especial, tuvo lugar con ocasión de la reclamación de Chile por la promulgación en el Perú de la Ley No 27.614 de Impuesto a las Ventas y el Consumo (DS 255 Trato fiscal aplicado a determinados productos importados), que eximía de este tributo a determinados bienes comestibles de primera necesidad producidos en el Perú, pero no así a los productos importados, lo que implicaba -a juicio de Chile- una vulneración al Principio del Trato Nacional que rige en el GATT.

En abril del año 2002 Chile solicitó consultas al Perú para resolver esta infracción al sistema multilateral de comercio, las que no surtieron efectos positivos. A raíz de lo anterior, Chile solicitó la formación de un Grupo Especial para resolver la diferencia, requerimiento que luego fue desistido, toda vez que Perú había eliminado la normativa impugnada. 
El Grupo Especial, si es que no se ha llegado a acuerdo entre las partes, emitirá un Informe Preliminar, que puede ser objeto de observaciones por reclamante y reclamado, luego de cuyo reexamen emitirá su Informe Definitivo.

Este informe servirá como resolución del conflicto, a menos que la totalidad de los miembros del OSD estime lo contrario. He aquí un cambio fundamental con el sistema dado por el GATT de 1947, ya que bajo el alero de aquel, la regla que regía era precisamente la contraria, puesto que para hacer suya la medida dictaminada por el grupo especial era necesario que esta fuese respaldada por todos los miembros signatarios del GATT, incluso de aquel cuya inobservancia al tratado estaba siendo cuestionada, lo que en los hechos la hacía muy poco eficaz.

Con el actual sistema se ha establecido un mecanismo que se ha denominado de consenso negativo, esto es el OSD hace suya la medida dictaminada por el grupo especial, a menos que la totalidad de sus miembros la rechace, lo que no se ha dado nunca ${ }^{26}$.

Ahora bien, además de este grupo especial, el marco dado por la OMC también estableció un sistema de apelación a la solución por este arribada.

La apelación tiene la particularidad de que solo se limita a la objeción de asuntos de Derecho ${ }^{27}$, los hechos quedaron fijados ante el Grupo Especial. El encargado de conocer el recurso de apelación deducido es el Órgano Permanente de Apelación (OPA), compuesto por siete miembros representativos de los diferentes sistemas jurídicos del orbe $^{28}$, que tienen una duración en su cargo de 4 años, reelegibles en una ocasión. Dentro de estos miembros, tres de ellos conocerán el asunto sometido al recurso de apelación respectivo.

La resolución o informe que en definitiva se adopte, ya sea del grupo especial o del órgano de apelación, ambas refrendadas por el OSD (a menos que la totalidad de los

\footnotetext{
${ }^{26}$ Fernando Piérola menciona que por este motivo hay autores que han señalado que con esta regla del consenso negativo tiene lugar en la especie una automaticidad de las resoluciones adoptadas por los grupos especiales. PIÉROLA CASTRO, Fernando. op. cit. (n. 19), p. 73.

27 A este respecto el artículo 17.6 del ESD dispone: "La apelación tendrá únicamente por objeto las cuestiones de derecho tratadas en el informe del grupo especial y las interpretaciones juridicas formuladas por este".

Con todo, debemos tener presente que la limitación del conocimiento por parte del Órgano Permanente de Apelación a asuntos de Derecho no es un tema pacífico en doctrina ya que ha habido autores, como menciona el profesor Piérola: "Existen voces de desacuerdo con esta limitación en la jurisdicción del Órgano de Apelación que responde a limitar su función a lo esencial para así reducir el tiempo de los procedimientos. De este modo se propone que se permita el reenvío de la materia controvertida cuando existan elementos de hecho no recogidos por el grupo especial. Los problemas que plantean las limitaciones estructurales en la jurisdicción del Órgano de Apelación generan inconvenientes para las partes cuando el Órgano de Apelación tiene que declinar en el conocimiento de un caso por falta de los elementos de hecho necesarios para fallar. Definitivamente, esta situación atenta contra la función del mecanismo de solución de diferencias de proveer una solución pronta que mantenga el equilibrio de los derechos y deberes de las partes, en tanto que al concluirse un caso por deficiencias en el análisis factual del grupo especial, las partes deberían iniciar de nuevo la controversia desde cero". Pierola CASTro, Fernando. op. cit. (n. 19), p. 81.

${ }^{28} \mathrm{El}$ Art. 17.3, Examen en Apelación del ESD señala: “3. El Órgano de Apelación estará integrado por personas de prestigio reconocido, con competencia técnica acreditada en derecho, en comercio internacional y en la temática de los acuerdos abarcados en general. No estarán vinculadas a ningún gobierno. Los integrantes del Órgano de Apelación serán representativos en términos generales de la composición de la OMC. Todas las personas que formen parte del Órgano de Apelación estarán disponibles en todo momento y en breve plazo, y se mantendrán al corriente de las actividades de solución de diferencias y demás actividades pertinentes de la OMC. No intervendrán en el examen de ninguna diferencia que pueda generar un conflicto directo o indirecto de intereses".
} 
miembros la rechace, consenso negativo ${ }^{29}$ ), propondrá medidas tendientes a que cese la conducta que constituya una infracción a las normas de la OMC, llevada a cabo por un Estado miembro, que suscitó el conflicto. Se deja, en todo caso, entregado al acuerdo de las partes la implementación de medida dentro de un "plazo prudencial"30 (art. 21.3 del ESD), el cual dependerá de las medidas a adoptar y los límites propios dentro del ordenamiento jurídico del Estado miembro impugnado.

Una diferencia comercial internacional que servirá para graficar los distintos pasos establecidos dentro del ESD, la podemos extraer de la DS 238 (Medidas de salvaguardia definitiva sobre importaciones de duraznos en conserva), en que Chile actuó como reclamante frente a la medida de salvaguardia a la importación de duraznos en conserva, adoptada por Argentina en julio del año 2001, por estimar que ella era atentatoria al Acuerdo sobre Salvaguardias y al Acuerdo General de Aranceles y Comercio.

La fase de consultas se comenzó a desarrollar en noviembre del año 2001, sin que a través de estas se lograse solucionar la controversia. A raíz de ello, Chile solicitó la designación de un Grupo Especial, cuyos miembros fueron designados en abril del año 2002.

En febrero del año 2003 el Grupo especial evacuó su informe, sosteniendo que la Argentina había actuado de manera incompatible con el Acuerdo sobre Salvaguardias y el Acuerdo General de Aranceles y Comercio, pues no se habrían demostrado fehacientemente los supuestos que habilitan para adoptar esa clase de medida excepcional.

Tal recomendación al no ser apelada por la Argentina, fue adoptada por el OSD de la OMC, acordándose que el plazo prudencial para hacer efectiva la modificación planteada vencía el 31 de diciembre del mismo año.

En enero del año 2004 Argentina comunicó al OSD que la salvaguardia impugnada fue retirada en diciembre del año 2003, con lo cual se daba por zanjado el conflicto, lo que fue aceptado por Chile.

Luego de esta exposición previa del procedimiento, nos parece interesante resaltar la fuerza que se ha señalado tiene el ESD de la OMC: "La característica más importante de este Acuerdo es, por tanto, la exigibilidad de los compromisos asumidos y la sujeción de los miembros a un procedimiento tendiente a penalizar los desvíos que limita de ese modo los criterios nacionales. La aplicación de las normas del GATT reposa, en parte, en la fuerza moral y política de los acuerdos internacionales pero también en la amenaza de retorsiones comerciales, las cuales pueden ser autorizadas frente a la violación de dichas normas" ${ }^{31}$.

\footnotetext{
${ }^{29}$ OMC. "Manual sobre sistema de solución de diferencias de la OMC", op. cit. (n. 14) p. 23. La metodología que se sigue en los hechos para el sistema del consenso negativo es que el presidente del OSD expone la resolución emanada del Grupo Especial (o del Órgano de Apelación) a los miembros integrantes, resolución que será tenida como decisión del OSD ante el silencio (consenso pasivo) o la objeción de uno o un gran número de Estados miembros (se requiere que la totalidad de los miembros la rechace). Hay autores (YU, Vicente Paolo. "La adopción de decisiones en la OMC ¿Sistema medieval o actualizado?, en: Foro Público de la OMC: 25 y 26 de septiembre de 2006. Ginebra, Organización Mundial de Comercio, pp. 6-7) que han criticado este mecanismo, pues estiman que las decisiones adoptadas en el seno de la OMC más que por omisión debiesen adoptarse por voto expreso de los Estados miembros, ya que así gozarían de mayor legitimidad.

${ }^{30} \mathrm{El}$ plazo prudencial puede determinarse de tres modos: a) ser propuesto por el Estado miembro afectado por la medida y adoptado por consenso por el OSD; b) fijarse de común acuerdo entre las partes dentro de los 45 días de la adopción del informe, o c) ser determinado por un árbitro. (art. 21.3 del ESD).

${ }^{31}$ FratAlocChi y ZuninO. op. cit. (n. 8), p. 53.
} 
En el supuesto de que el Estado impugnado no dé cumplimiento a lo resuelto, ni se alcance un acuerdo satisfactorio (compensaciones) temporal, voluntario y compatible con los Acuerdos abarcados, subsidiariamente se admite que el Estado afectado pueda privar temporalmente al Estado infractor de ciertos beneficios otorgados en virtud de los distintos acuerdos de la OMC en un sector productivo determinado (retorsión ${ }^{32}$ ), en principio, en el mismo sector productivo donde se produjo la infracción por el Estado impugnado. Si ello no fuera posible o si tal medida fuera manifiestamente ineficaz, se admite la suspensión de beneficios en otros sectores productivos, donde las consecuencias sean equivalentes (retorsión cruzada o intersectorial), esto es, que el daño que con la privación de los beneficios específicos sea proporcional al causado con la infracción originaria sometida al conocimiento de la OMC.

Sin embargo, es menester recalcar que el mecanismo de las retorsiones si bien es admitido, debe ser utilizado en subsidio, sí y solo sí, la eliminación o modificación de la medida impugnada no se produce, o bien si una compensación al Estado denunciante no tiene lugar o no resulta suficiente. Así se desprende de lo dispuesto en el art. 3.7 del ESD que nos dice:

\begin{abstract}
"Antes de presentar una reclamación, los Miembros reflexionarán sobre la utilidad de actuar al amparo de los presentes procedimientos. El objetivo del mecanismo de solución de diferencias es hallar una solución positiva a las diferencias. Se debe dar siempre preferencia a una solución mutuamente aceptable para las partes en la diferencia y que esté en conformidad con los acuerdos abarcados. De no llegarse a una solución de mutuo acuerdo, el primer objetivo del mecanismo de solución de diferencias será en general conseguir la supresión de las medidas de que se trate si se constata que estas son incompatibles con las disposiciones de cualquiera de los acuerdos abarcados. No se debe recurrir a la compensación sino en el caso de que no sea factible suprimir inmediatamente las medidas incompatibles con el acuerdo abarcado y como solución provisional hasta su supresión. El último recurso previsto en el presente Entendimiento para el Miembro que se acoja a los procedimientos de solución de diferencias es la posibilidad de suspender, de manera discriminatoria contra el otro Miembro, la aplicación de concesiones o el cumplimiento de otras obligaciones en el marco de los acuerdos abarcados siempre que el OSD autorice la adopción de estas medidas".
\end{abstract}

\footnotetext{
32 Gamboa y Fernández definen la retorsión, citando a Manuel Sierra, como: "la respuesta contra actos que, pudiendo ser realizados legalmente por un Estado, son la evidencia de un sentimiento inamistoso o colocan a los súbditos de un estado en una situación de inferioridad material o moral respecto de los otros", GAMBOA SERAZZI, Fernando y FERNÁNDEZ Undurraga, Macarena. Tratado de Derecho Internacional Público y Derecho de Integración. Santiago: LexisNexis, 2005. p. 620. Por su parte el profesor Benadava refiriéndose a las represalias o contramedidas nos dice: "La represalia es un acto ilícito realizado por un Estado en contra de otro Estado y que encuentra su justificación excepcional en el hecho de que responde a un acto ilícito cometido previamente por el Estado contra el cual se dirige. Las represalias tienden a poner término a una lesión jurídica, a obtener una reparación por ella o a prevenir una nueva (...) En el ámbito internacional, en que no hay un sistema judicial y coercitivo orgánico, los Estados pueden reaccionar por sí mismos ante la violación de sus derechos, pero dentro de los límites que el derecho internacional les impone", BenadaVA, Santiago. Derecho Internacional Público. -6a ed.- Santiago, Editorial Jurídica ConoSur, 1999, p. 151.
} 
Luego, en lo que atañe a las compensaciones retorsiones propiamente tal, el artículo 22 del ESD dispone:

"1. La compensación y la suspensión de concesiones u otras obligaciones son medidas temporales a las que se puede recurrir en caso de que no se apliquen en un plazo prudencial las recomendaciones y resoluciones adoptadas. Sin embargo, ni la compensación ni la suspensión de concesiones u otras obligaciones son preferibles a la aplicación plena de una recomendación de poner una medida en conformidad con los acuerdos abarcados. La compensación es voluntaria y, en caso de que se otorgue, será compatible con los acuerdos abarcados.

2. Si el Miembro afectado no pone en conformidad con un acuerdo abarcado la medida declarada incompatible con él o no cumple de otro modo las recomendaciones y resoluciones adoptadas dentro del plazo prudencial determinado de conformidad con el párrafo 3 del artículo 21, ese Miembro, si así se le pide, y no más tarde de la expiración del plazo prudencial, entablará negociaciones con cualesquiera de las partes que hayan recurrido al procedimiento de solución de diferencias, con miras a hallar una compensación mutuamente aceptable. Si dentro de los 20 días siguientes a la fecha de expiración del plazo prudencial no se ha convenido en una compensación satisfactoria, cualquier parte que haya recurrido al procedimiento de solución de diferencias podrá pedir la autorización del OSD para suspender la aplicación al Miembro afectado de concesiones u otras obligaciones resultantes de los acuerdos abarcados".

Debemos tener presente que la retorsión o compensación requerida debe ser moderada, si el Estado infractor es un país menos adelantado o en vías de desarrollo, conforme a lo establecido en el art. 24 del ESD.

Otra controversia ventilada ante la OMC que nos servirá para exponer los diferentes pasos, incluyendo la retorsión, como medida de excepción, admitida -como vimos- en el ESD tuvo lugar con la Diferencia DS 217 (Ley de compensación por continuación del dumping o mantenimiento de las subvenciones del año 2000). En este conflicto, a fines del año 2000, Chile junto a Australia, Brasil, la Comunidad Europea, Corea, India, Indonesia, Japón y Tailandia solicitaron consultas respecto a la modificación de la Ley Arancelaria de Estados Unidos, a través de la "Ley enmienda Byrd"33, ya que con esta modificación se estaban vulnerando distintas normas en materia de dumping, subvenciones y medidas compensatorias de la OMC.

En julio del año 2001 las partes reclamantes solicitaron el establecimiento de un grupo especial, para que conociera la controversia, grupo especial que debió ser nombrado por el Director General de la OMC en octubre del año 2001, atendida la falta de acuerdo entre las partes para la nominación de sus integrantes.

En septiembre del año 2002 el Grupo Especial emitió un informe, estableciendo que la normativa impugnada por los reclamantes era contraria a los acuerdos de la OMC,

\footnotetext{
33 Biggs, Gonzalo. "El procedimiento de solución de controversias de la OMC. La experiencia de América Latina y el Caribe”, en: Revista de la CEPAL, No 86, agosto 2005, Santiago, p. 82.
} 
anulando o menoscabando los derechos surgidos del sistema multilateral de comercio. A raíz de lo anterior, se recomendaba a Estados Unidos que modificara su normativa para hacerla armónica con las reglas y acuerdos de la OMC.

Sin embargo, Estados Unidos apeló dicha resolución en octubre del año 2002.

El Órgano Permanente de Apelación emitió su dictamen en enero del año 2003, confirmando el informe del Grupo Especial, en cuanto a que la enmienda en la legislación norteamericana resultaba atentatoria al Acuerdo Antidumping y el sistema de subvenciones de la OMC, por lo que recomendaba su modificación.

En marzo del año 2003 los reclamantes solicitaron se nombrase un árbitro, con la finalidad que determine el plazo prudencial dentro del cual Estados Unidos debía modificar su normativa interna, para hacerla coherente con las reglas de la OMC, llegando este a la conclusión que tal plazo vencía en diciembre de ese año.

En enero del año 2004 Estados Unidos comunicó que había alcanzado un acuerdo con Australia, Indonesia y Tailandia prorrogando el plazo antes mencionado hasta diciembre del año 2004. Ante lo cual Chile y otros países reclamantes solicitaron al Órgano de Solución de Diferencias de la OMC que los habilitara para suspender concesiones conferidas a Estados Unidos en virtud de los Acuerdos de la OMC, ya que el referido convenio en que se prorrogaba el plazo a los Estados Unidos no había contado con su venia. Ante esta solicitud se habilitó a Chile para suspender concesiones imponiendo un arancel adicional a los productos provenientes de Estados Unidos, en base a una ecuación determinada.

Fue solo en febrero del año 2006 cuando Estados Unidos dio efectivo cumplimiento a las recomendaciones dadas por el Órgano de Solución de Diferencias de la OMC, dejando sin efecto la enmienda efectuada a su Ley Arancelaria.

En mérito a lo expuesto, podría sostenerse que las sanciones contempladas en el ESD, no parecieran ser mecanismos efectivos que desincentiven la violación de las normas de la $\mathrm{OMC}^{34}$, no da la impresión que sea una solución que estimule fuertemente a un Estado miembro a cumplir los compromisos asumidos como miembro de la OMC. Habida cuenta, además, de las continuas presiones a que habitualmente quedan sometidos los gobiernos por sus sectores productivos locales que buscan la creación de normas proteccionistas para sus industrias ${ }^{35}$.

"Es claro que los grupos de interés de carácter proteccionista han mejorado sus estrategias. Ahora, en vez de hablar abiertamente de protección comercial, prefieren disfrazar sus intenciones con la promoción de objetivos sociales generalmente com-

\footnotetext{
34 Un análisis bastante crítico respecto al sistema de solución de controversias establecido bajo el marco de la OMC, en particular, la posición que dentro de él juegan los países en vías de desarrollo en detrimento de los países desarrollados puede encontrarse en CADENA AFANADOR, Walter. op. cit. (n. 12), pp. 161-162; Ver el excelente trabajo de BláZQUEZ NAVARRO, Irene. "Cumplimiento del Derecho Internacional en el sistema de solución de diferencias de la OMC", en: Revista Española de Derecho Internacional, Vol. LVIII- 2006, Núm. 1, Boletín Oficial del Estado; Madrid, 2007, pp. 184, 203.

35 Véase, a modo de ejemplo en: "Iansa Defiende Renegociar el Arancel Consolidado ante OMC", <en línea> El Mercurio en internet. 6 de noviembre, 2000. Disponible en la Worl Wide Web: <http://diario.elmercurio.cl/detalle/ index.asp?id=\%7Bbf77bde4-a3e4-421d-b56b-212ba9ae9ae1\%7D>; "El azúcar, otro punto de discordia en el MERCOSUR”, <en línea> La Nación en internet. 21 de abril, 1997. <http://www.lanacion.com.ar/nota.asp?nota_id=67462>; EDITORIAL. "El proteccionismo al acecho", <en línea> La Nación en internet. 2 de marzo, 2009. <http:// www.lanacion.com.ar/nota.asp?nota_id=1104531>
} 
partidos como la protección del medio ambiente, los derechos de los trabajadores y en ocasiones hasta la libertad religiosa. Aunque esto no quiere decir que todos los que defienden dichos valores sean proteccionistas" 36 .

Refiriéndose precisamente a la eficacia de este tipo de medidas el destacado autor peruano Fernando Piérola ${ }^{37}$ sostiene: "La suspensión de concesiones puede servir como un mecanismo de disuasión de conductas oportunistas cuando existe amenaza creíble de retaliación. Sin embargo, cuando se trata de países con bajos montos de comercio, que por el contrario dependen de las importaciones del país demandado, resulta difícil considerar que esos países se encuentran en la capacidad de retaliar. Esta situación plantea serias interrogantes con respecto a la eficacia del sistema de retaliación para países en desarrollo. Sin embargo, la existencia del Acuerdo sobre los ADPIC facilita una salida para países de volumen comercial relativamente moderado en tanto que, sin perjudicar sus importaciones, pueden ejercer presión sobre un aspecto sensible para países desarrollados, como lo es la intangibilidad de los derechos de propiedad intelectual. Al respecto es interesante apreciar la estrategia que tomó Ecuador en el asunto CE-Bananas cuando solicitó al OSD la suspensión de concesiones comerciales no solo en el marco del comercio de bienes y servicios, sino también en los referente a la protección de derechos de propiedad intelectual bajo el Acuerdo de los ADPIC".

Quizás por lo anterior se ha señalado que el sistema de solución de controversias establecido por la $\mathrm{OMC}$ es un sistema cuasi jurisdiccional ${ }^{38}$, ya que en él no existe un poder de imperio efectivo ${ }^{39}$ que, a través de mecanismos de coerción, incentiven a dar cumplimiento inmediato a lo resuelto (o desincentiven la desobediencia a la norma). El cumplimiento, en el fondo, quedará entregado a los tiempos y buena voluntad que le dé el mismo Estado infractor, que en caso de ser una potencia económica no se verá especialmente afectado por una eventual retorsión que adopte una economía menor ${ }^{40}$.

En sistema del ESD, dado el carácter interestatal de las partes involucradas, se busca la mayor flexibilidad posible, para que en definitiva, sean las mismas partes involucradas

\footnotetext{
${ }^{36}$ DE LA PEÑa, Alejandro. "Principales retos para el sistema multilateral de comercio en los próximos años" en: Foro Internacional, Volumen XLI, Número 2, Colegio de México, Ciudad de México, 2001. p. 253.

37 Piérola Castro, Fernando. "Solución de diferencias en la Organización Mundial de Comercio”. op. cit. (n. 19), pp. 143-144. Refiriéndose a esta misma temática el profesor Arteaga nos señala: "El problema de estas suspensiones, que tienen por objeto equilibrar los beneficios y concesiones asumidas recíprocamente entre las partes, es que los países menos desarrollados y más abiertos al comercio internacional son proporcionalmente más afectados que los países más desarrollados y menos dependientes del comercio internacional. Es así como para graficar un ejemplo extremo, si Estados Unidos infringe todas sus obligaciones y concesiones a que se encuentra obligado para con Chile según los tratados administrados por la OMC, Chile puede en última instancia, y siguiendo el procedimiento aquí analizado, suspender todas las obligaciones y concesiones que a su vez se encuentra obligado por esos mismos tratados para con Estados Unidos. Así, de este modo se restablece el equilibrio entre las concesiones de ambos países, pero lógicamente se produce un efecto negativo mayor en la economía chilena que en la economía americana dado los volúmenes de producción y comercio de cada uno de ellos”, Arteaga ECHEverría, Ignacio. op. cit. (n. 13), pp. 22-23.

38 BASALDÚA, Ricardo Javier. op. cit. (n. 8), p. 536.; OMC, op. cit. (n. 13), p. 26.

39 BIGGS, Gonzalo. "El procedimiento de solución de controversias de la OMC. La experiencia de América Latina y el Caribe", op. cit. (n. 33), p. 71.

40 Se ha señalado: "Los problemas de instrumentación son particularmente importantes para los miembros con pequeñas o medianas economías que no pueden recurrir a la retorsión para hacer valer sus derechos como lo pueden hacer los más grandes", DE LA PEÑA, Alejandro, op. cit. (n. 36), p. 251.
} 
las que alcancen un acuerdo que logre salvar el impase, con la premisa fundamental que los alcances de aquel acuerdo no puede ser discriminatorio a favor de tal o cual Estado en particular ${ }^{41}$, sino que los efectos de él se harán aplicables a los demás miembros de la OMC en virtud de la Cláusula de la Nación más Favorecida, contenida en el artículo 1 del Acuerdo General sobre Comercio de Mercaderías, el art. 2 del Acuerdo General sobre Comercio de Servicios y el art. 4 del Acuerdo sobre Propiedad Intelectual relativa al Comercio, principio rector del sistema multilateral de comercio. Para garantizar que los acuerdos alcanzados no perjudiquen a los demás miembros de la OMC, es que se exige que cada etapa del proceso sea aprobada por el OSD, representante de la multilateralidad inherente de la OMC. Lo que se grafica con lo dispuesto por el artículo 3.6 del ESD señala: "Las soluciones mutuamente convenidas de los asuntos planteados formalmente con arreglo a las disposiciones en materia de consultas y solución de diferencias de los acuerdos abarcados se notificarán al OSD y a los Consejos y Comités correspondientes, en los que cualquier Miembro podrá plantear cualquier cuestión con ellas relacionada”.

Otras críticas que se formulan al ESD dicen relación con el carácter secreto o confidencial de los procedimientos, tanto a nivel de consultas, de Grupo Especial, como también ante el Órgano de Apelación. Además, se ha cuestionado que los sujetos legitimados a iniciar un proceso bajo este sistema necesariamente han de ser los Estados, y no organizaciones no gubernamentales, empresas, o particulares.

El sistema de ESD de la OMC es diferente al formulado por otros mecanismos de solución de controversias que regulan materias económicas internacionales, donde además de conminarse al Estado infractor a modificar su conducta se da cabida a la imposición de una sanción pecuniaria. Un ejemplo de ello se da en el sistema de solución de controversias para problemas respecto a inversión extranjera, que sirven de marco para el CIADI (Centro Internacional de Arreglo de Diferencias de Inversión) ${ }^{42}$ dependiente del Banco Mundial. Dentro de él se ha admitido la procedencia de la fijación de cuantiosas indemnizaciones a favor de un sujeto o entidad a quien le han sido violentados sus derechos como inversionista extranjero. Clarificador en esta materia resulta ser el caso Víctor Pey Casado por el diario Clarín contra el Estado de Chile ${ }^{43}$, cuya resolución condenó al Estado chileno a pagar una suma de más de 16 millones de dólares norteamericanos, por concepto de indemnización.

Sin embargo, no debemos dejar de tener presente que la naturaleza de uno y otro pleito es diferente, ya que, el sistema de la OMC tiene como partes litigantes a dos Estados, mientras que el sistema contemplado en el CIADI apunta principalmente a que una persona natural o jurídica inversionista extranjero que vea vulnerados los derechos de que goza en esta condición pueda acudir ante un tribunal internacional, para así tener una

\footnotetext{
${ }^{41}$ SALINAS BuRgos, Hernán. "Solución de controversias en acuerdos sobre libre comercio. Derecho aplicable y su relación con el sistema de la Organización Mundial de Comercio", en: Jornadas de Derecho Internacional: 29 de noviembre a 2 de diciembre de 2004. Santiago, Organización de Estados Americanos y Sociedad Chilena de Derecho Internacional, 2005. p. 102.

42 MORALES, Joaquín. "Solución Internacional de controversias en materia de inversiones CIADI o UNCITRAL, ¿Cuál camino escoger?", en: Jornadas de Derecho Internacional: 29 de noviembre a 2 de diciembre de 2004. Santiago, Organización de Estados Americanos y Sociedad Chilena de Derecho Internacional, 2005. pp. 107-115.

43 Para ver una exposición de los hechos en controversia y los pasos procesales seguidos hasta el año 2004 ver. MAYORGA, Roberto, MORAlES, Joaquín y POLANCO, Rodrigo. Inversión Extranjera. Régimen Jurídico y Solución de Controversias. Santiago: LexisNexis, 2005, pp. 263-264.
} 
mayor imparcialidad a la hora de resolver el asunto, supuestos todos que no se dan en un conflicto interestatal.

Pese a todo los defectos que pueda encontrársele a este mecanismo de solución de controversias, analizado desde el punto de vista de la sanción que impone o si se quisiera ser aventurado en la aseveración la falta de una sanción efectiva, entendida esta como un desincentivo para desarrollar tal o cual conducta, tales críticas no tienen lugar solo para el mecanismo contemplado por la OMC, puesto que en diferentes tratados de libre comercio y esquemas regionales de integración se han adoptado, dado el carácter interestatal, criterios similares ${ }^{44}$. Así por ejemplo, en el caso del Tratado de Libre Comercio entre Chile y Estados Unidos, si uno de los Estados contratantes estima que, en virtud de una medida adoptada, se está contraviniendo el Tratado se anulan o menoscaban los beneficios que razonablemente pudo haber esperado de la aplicación de ciertas disposiciones del mismo, dicho Estado estará legitimado para acudir al sistema arbitral de solución de controversias contemplado en este acuerdo, que entrega el conocimiento del asunto a un Grupo Arbitral. Si este Grupo Arbitral estima que es efectiva la acusación y resuelve que la medida impugnada debe modificarse o dejarse sin efecto, en tal evento si dicha resolución no es cumplida por la parte vencida dentro de un plazo prudente, también se da lugar a un procedimiento de retorsiones, como mecanismo coercitivo, manifestado a través de la suspensión de beneficios arancelarios otorgados en virtud del mismo Tratado ${ }^{45}$.

A este respecto el profesor Jorge Witker señala: "Cuando las partes no acuerden una compensación o han ya acordado una compensación o un plan de acción y la parte reclamante considera que la parte demandada no cumple con los términos del acuerdo, entonces la parte reclamante podrá notificar a la otra su intención de suspender los beneficios, especificando su nivel.

En caso de que la parte demandada considere que el nivel de beneficios que se pretende suspender es excesivo; o ha eliminado la disconformidad, la anulación o el menoscabo identificado en el informe puede solicitar que el grupo arbitral se vuelva a reunir en los 30 días siguientes a la notificación de la suspensión de beneficios" ${ }^{46}$.

Similar situación se da en el sistema de solución de controversias general establecido en el Acuerdo de Asociación Estratégica firmado entre Chile y la Unión Europea, donde también se sigue un mecanismo bastante semejante al dado bajo el seno de la $\mathrm{OMC}^{47}$. Este sistema también persigue que sean las partes las que alcancen una solución.

"Esta modalidad se ha establecido sobre la base de la voluntad de las Partes de llegar a un acuerdo sobre la interpretación y aplicación de la Parte IV del Acuerdo y, a

\footnotetext{
44 Debemos tener presente que estos Tratados actúan en paralelo a los de la OMC, e incluso se puede señalar que están dentro del marco de la OMC, motivo por el cual ante un conflicto determinado las partes podrán elegir el foro ante el cual acudir para resolver su discrepancia, todo ello con la salvedad de que una vez que se ha elegido un foro determinado no podrá recurrir a otro mecanismo de solución de controversias GAMBOA SERAZZI, Fernando - FERNÁNDEZ UNDURRAGA, Macarena. op. cit. (n. 32), pp. 757-758.

45 Ibid., p. 763.

46 WiTKER, Jorge. Solución de Controversias Comerciales en el Tratado de Libre Comercio Chile-Estados Unidos. Santiago: LexisNexis, 2005, p. 30.

47 Baierlein Hermida, Hugo. Chile-Unión Europea ¿Cómo aprovechar el Acuerdo?. Santiago: LexisNexis, 2003 , p. 208.
} 
través de mecanismos de cooperación y consulta, evitar ${ }^{48}$ y resolver las diferencias entre ellas y lograr una solución mutuamente satisfactoria de cualquier asunto que pudiere afectar a su funcionamiento ${ }^{49}$. A estos efectos, cada Parte podrá solicitar la celebración de consultas en el seno del Comité de Asociación, Órgano responsable de este procedimiento, el cual debe actuar con plazos muy precisos" 50 .

Si no se alcanza una solución entre las partes, la controversia se somete al conocimiento de un Grupo Arbitral (seleccionado de una lista elaborada por el Comité de Asociación ${ }^{51}$ ), de cuyo proceso emanará un laudo respectivo. En el evento de que el laudo no sea acatado y no se adopten las medidas tendientes a eliminar el menoscabo producido por la conducta impugnada, las normas de este Acuerdo también contemplan un sistema de suspensión de beneficios concedidos en virtud del Acuerdo de Asociación, similar al establecido en el ESD de la $\mathrm{OMC}^{52}$. Sobre este punto, el artículo 188 en su numerales 6 y 7 de este Acuerdo de Asociación Estratégica resulta esclarecedor:

6. Si la Parte de que se trate no notifica las medidas de aplicación antes de la expiración del plazo razonable o si el grupo arbitral dictamina que las medidas de ejecución notificadas por la Parte de que se trate son incompatibles con sus obligaciones en virtud de esta Parte del Acuerdo, la Parte requirente, si no se hubiera llegado a un acuerdo sobre la compensación, estará facultada para suspender la aplicación de beneficios otorgados en virtud de esta Parte del Acuerdo equivalentes al nivel de anulación o menoscabo causado por la medida que se considera que infringe esta Parte del Acuerdo.

7. Al considerar qué beneficios se van a suspender, la Parte requirente tratará de suspender en primer lugar beneficios en el mismo Título o Títulos de esta Parte del

\footnotetext{
${ }^{48} \mathrm{He}$ aquí una particularidad ya que el Acuerdo de Asociación Estratégica entre Chile y la Unión Europea no solamente habilita para requerir consultas cuando ya se ha provocado la anulación o menoscabo, ya que también se admite este expediente cuando hay una amenaza a que ello se produzca, lo que puede tener lugar en el caso de la medida sea un proyecto próximo a entrar en vigor.

Lo anterior se desprende de lo prescrito por el art. 183.2 del Acuerdo que señala: "Cada Parte podrá solicitar la celebración de consultas en el Comité de Asociación respecto de cualquier medida existente o en proyecto o cualquier asunto relativo a la aplicación o la interpretación de esta Parte del Acuerdo o cualquier otro asunto que considere que puede afectar a su funcionamiento. A los efectos del presente Título, el término "medida" incluirá también una práctica. La Parte determinará en la solicitud la medida u otro asunto por el que reclama, indicará las disposiciones del presente Acuerdo que considera aplicables y entregará la solicitud a la otra Parte" (el subrayado es nuestro).

A nuestro juicio, esta alternativa resulta bastante provechosa, ya que permite prevenir un conflicto entre las partes.

49 El art. 184.1 del Acuerdo de Asociación Estratégica lo señala expresamente: "Las Partes procurarán en todo momento llegar a un acuerdo mutuamente satisfactorio sobre la controversia".

Coherente con ello resulta lo establecido en el art. 187.7 del mismo Acuerdo, que prescribe: "La Parte requirente, con el acuerdo de la Parte requerida, podrá retirar su reclamación en todo momento antes de que el laudo sea remitido a las Partes y al Comité de Asociación. Dicho retiro será sin perjuicio de su derecho a presentar una nueva reclamación en relación con el mismo asunto en una fecha posterior", disposición que deja en claro que el control del desarrollo del proceso está entregado a los litigantes.

${ }^{50}$ Leiva Lavalle, Patricio. La Asociación Estratégica Chile-Unión Europea. Santiago, CELARE, 2003. p. 148.

${ }^{51}$ El Comité de Asociación es un órgano surgido del Acuerdo de Asociación Estratégica encargado de la aplicación general del Acuerdo. Se compone por representantes de los miembros de del Consejo de la Unión Europea y de la Comisión de las Comunidades Europeas, por una parte, y por representantes del gobierno de Chile por la otra.

52 Gamboa Serazzi, Fernando - FernándeZ Undurraga, Macarena. op. cit. (n. 32), p. 761.
} 
Acuerdo que resultaron afectados por la medida que el grupo arbitral determinó que infringía las disposiciones de esta Parte del Acuerdo. La Parte requirente que considere que no resulta factible o efectivo suspender beneficios en el mismo Título o Títulos podrá suspender beneficios en otros Títulos, siempre que lo justifique por escrito. Al seleccionar los beneficios que se vayan a suspender, se dará prioridad a los que menos perturben el funcionamiento del presente Acuerdo.

En lo que atañe a los sistemas de integración regional, el MERCOSUR, que nació a través del Tratado de Asunción de 1991, ha regulado también las eventuales controversias comerciales suscitadas entre sus miembros. Así en un primer momento, se reguló por normas generales contempladas en este mismo acuerdo constitutivo, luego a través del Protocolo de Brasilia ${ }^{53}$ y actualmente, a partir del año $2004^{54}$, a través del Protocolo de Olivos ${ }^{55}$ que

53 REY CARO, Ernesto. "Los mecanismos y procedimientos para la solución de controversias en el MERCOSUR. Antecedentes, realidad y perspectivas”, en: PUEYO, J. y REY CARO, E. (Coords). MERCOSUR: Nuevos ámbitos y perspectivas en el desarrollo del proceso de integración. Buenos Aires, Editorial Ciudad Argentina, 2000, pp. 95-146.; RUIZ DíAZ LABRANO, Roberto. MERCOSUR. Integración y Derecho. Buenos Aires: Editorial Ciudad Argentina, 1998. p. 535-555.

54 Gattinoni De Mujía, María. "La aplicación judicial del Derecho Mercosur en casa uno de los Estados parte. Algunas consideraciones sobre las reformas introducidas por el Protocolo de Olivos". En: Jornadas de Derecho Internacional: 29 de noviembre a 2 de diciembre de 2004. Santiago, Organización de Estados Americanos y Sociedad Chilena de Derecho Internacional, 2005. p. 3-27.

55 El sistema creado por el Protocolo de Olivos se caracteriza al igual que el sistema de la OMC, porque busca el acuerdo y negociación directa entre las partes, para lo cual se contempla un término de quince días (artículo 5); si transcurrido este plazo las partes no han alcanzado acuerdo, se permite a cualquiera de estas que pueda iniciar un procedimiento arbitral o bien someter el conflicto al conocimiento del Grupo de Mercado Común, entidad que formulará recomendaciones tendientes a solucionar el diferendo dentro de un plazo no superior a treinta días (artículos 6, 7 y 8).

En el caso que se opte por acudir al arbitraje, se establecerá un Tribunal Ad Hoc compuesto por tres árbitros dentro de una lista previamente establecida (uno nombrado por cada parte y un tercero nombrado de común acuerdo, que presidirá el tribunal) (artículos 10 y 11); El Tribunal Arbitral Ad Hoc dictará el laudo en un plazo de sesenta días, prorrogables por decisión del Tribunal por un plazo máximo de treinta días, contado a partir de la comunicación efectuada por la Secretaría Administrativa del Mercosur a las partes y a los demás árbitros, informando la aceptación por el árbitro Presidente de su designación (artículo 16).

El laudo arbitral es susceptible de ser recurrido de revisión, para que un Tribunal Permanente de Revisión conozca de cuestiones de Derecho impugnadas (artículo 17).

En lo que atañe a la obligatoriedad del laudo, ya sea del Tribunal Arbitral ad hoc o aquel emanado del Tribunal Permanente de Revisión, este es obligatorio para las partes. A ello se refiere el artículo 26 de este Protocolo, que señala: "1. Los laudos de los Tribunales Arbitrales Ad Hoc son obligatorios para los Estados partes en la controversia a partir de su notificación y tendrán, con relación a ellos, fuerza de cosa juzgada si transcurrido el plazo previsto en el Artículo 17.1 para interponer el recurso de revisión, este no fuere interpuesto.

2. Los laudos del Tribunal Permanente de Revisión son inapelables, obligatorios para los Estados partes en la controversia a partir de su notificación y tendrán, con relación a ellos, fuerza de cosa juzgada".

Luego, el artículo 27 dispone: "Los laudos deberán ser cumplidos en la forma y con el alcance con que fueron dictados. La adopción de medidas compensatorias en los términos de este Protocolo no exime al Estado parte de su obligación de cumplir el Laudo".

Los laudos de los Tribunales Ad Hoc o los del Tribunal Permanente de Revisión, según el caso, deberán ser cumplidos en el plazo que los respectivos tribunales establezcan. Si no se determinara un plazo, los laudos deberán ser cumplidos dentro de los treinta días siguientes a la fecha de su notificación. (artículo 29.1)

Si no obstante ello la parte vencida no cumpliere con lo resuelto en el Laudo dentro del plazo de un año, se permite que la parte vencedora adopte medidas compensatorias temporales, tales como la suspensión de concesiones u otras obligaciones equivalentes, en principio en el mismo sector afectado, cuya impugnación dio lugar al conflicto (artículo 31).

Una particularidad de este sistema estriba en que se admite que personas naturales o jurídicas particulares también sean legitimados activos para poder dar inicio al procedimiento de solución de controversias establecido en este Protocolo (artículos 39 y siguientes), he aquí una diferencia sustancial con el sistema de la OMC. 
ha establecido un mecanismo, caracterizado por seguir los pasos -también- del sistema establecido por el ESD de la OMC, en cuanto a que se busca, en primer lugar, que las partes alcancen una solución al conflicto, en su defecto se admite que se someta la controversia al Grupo Mercado Común ${ }^{56}$ o a un Tribunal Arbitral Ad hoc. Este último, dentro de un plazo determinado deberá zanjar el conflicto y emitir su laudo. Dicho laudo es susceptible de ser impugnado a través de un recurso de revisión, que se limitará a cuestiones de Derecho, en similares condiciones al recurso de apelación de la OMC.

En caso que la parte vencida no dé cumplimiento a lo resuelto por el Tribunal Arbitral Ad hoc o el Tribunal Permanente de Revisión, al igual que como ocurre en el ESD de la OMC, se admite que, como mecanismo de retorsión, la parte vencedora pueda suspender medidas y beneficios otorgados al Estado infractor conferidas en virtud de la normativa de Mercosur.

En mérito a lo señalado nos parece adecuado adherir a las ideas formuladas por el profesor Morales Barría ${ }^{57}$ quien señala: "Entre estados, la responsabilidad internacional económica no puede operar como entre privados, pues resulta en definitiva imposible poner a un estado entre la espada y la pared, especialmente si se trata de grandes potencias. Por ello, lo que en definitiva determina la responsabilidad económica, es la negociación internacional económica, que se produce en los diferentes sistemas de solución de diferencias. La paradoja es que, para sancionar a un estado, en definitiva, hay que negociar con él su sanción. El estado pasa a ser así, juez y parte”.

Con todo y aun cuando el sistema de solución de controversias de la OMC y los otros acuerdos internacionales que lo siguen de cerca presentan un sistema de sanciones que no pareciere resultar un estímulo suficiente para dar cumplimiento de sus obligaciones (si el cumplimiento de estas se miran como el costo beneficio entre la utilidad que me irroga el cumplir una obligación versus la eventual sanción por no cumplirla), no podemos olvidar un Principio rector de todo el Derecho, tanto nacional como internacional, cual es la Buena fe, que en el caso específico del ESD de la OMC resulta a todas luces aplicables, ya sea porque se entienda que este es un principio consuetudinario que rige las relaciones entre Estados, como también por lo por lo señalado por el artículo 3.2. del ESD que dispone que este sistema debe interpretarse conforme a las normas usuales de interpretación del Derecho Internacional Público, lo que nos remite a la Convención de Viena sobre derecho de los Tratados $^{58}$, cuyo artículo 31.1 nos llama a interpretar los tratados de buena fe, al decirnos:

\footnotetext{
56 El Grupo Mercado Común (GMC) es el órgano ejecutivo del Mercosur, encargado de ejecutar las decisiones adoptadas en el seno del Consejo del Mercado Común. Se compone por 4 representantes titulares y 4 alternos no ministeriales de los Estados miembros, representando a los Ministerios de Economía, Relaciones Exteriores y el Banco Central, coordinados por los Ministerios de Relaciones Exteriores respectivos (art. 13 a 15 Tratado de Asunción).

57 Morales Barría, Fernando. "La responsabilidad internacional económica del Estado de Chile está íntimamente ligada al excesivo bilateralismo", en: La Revista de Derecho, Universidad Central de Chile, Año X, No 7, Santiago, juliodiciembre 2004, p. 152.

58 "La referencia al Derecho internacional público legitima el procedimiento de solución de diferencias de la OMC en la medida que estas normas internacionales son observadas con carácter general, pero además porque introducen otras variables, como, por ejemplo, el hecho de que, a la hora de interpretar un tratado, "por mor" del artículo 31.3.c) de la Convención de Viena, el contexto comprenderá "toda norma pertinente de Derecho internacional aplicable en las relaciones entre las partes". Esto obliga a considerar otras normas jurídicas ajenas al Derecho OMC en su interpretación, reglas jurídicas que tal vez pueden llegar a priorizar unos valores distintos a la liberalización del comercio”. BLÁZQUEZ NAVARRO, Irene,. op. cit. (n. 34), p. 181.
} 


\section{"Un tratado deberá interpretarse de buena fe conforme al sentido corriente que haya de atribuirse} a los términos del tratado en el contexto de estos y teniendo en cuenta su objeto y fin".

Evidentemente que si atendemos al objeto y fin del sistema de solución de controversias contenido en el ESD, resulta imperativo entender que estos apuntan al efectivo cumplimiento de las obligaciones contraídas al adherir a la OMC, y no porque no haya un mecanismo efectivo que establezca sanciones pecuniarias (bajo la óptica de que estas se estimen con fuerza vinculante) las partes pueden vulnerar lo pactado.

La conclusión anterior cobra aún más fuerza si la misma Convención de Viena sobre derecho de los Tratados contempla expresamente la imperatividad de lo convenido (pacta sunt servanda), al decirnos en los artículos 26 y 27: 26. "Pacta sunt servanda". Todo tratado en vigor obliga a las partes y debe ser cumplido por ellas de buena fe.

27. El derecho interno y la observancia de los tratados. Una parte no podrá invocar las disposiciones de su derecho interno como justificación del incumplimiento de un tratado".

Por lo demás, del análisis de las variadas Diferencias sometidas al sistema de solución de diferencias del ESD, podemos percatarnos que pese a lo engorroso y duradero que pudiere parecer el procedimiento, en la mayoría de los casos expuestos las conductas impugnadas atentatorias contra las obligaciones internacionales fueron dejadas sin efecto, por así requerirlo el normal y armonioso ejercicio del comercio internacional. Más aún, en muchos casos no fue necesario llegar a un "veredicto" o decisión heterónoma del Grupo Especial o del Órgano de Apelación, ya que en un número significante de los casos el problema fue resuelto en la fase de consultas, lo que demuestra -en general- el respeto por lo convenido. Precisamente en mérito al respeto general a las obligaciones internacionales asumidas es que hoy la Ronda de Doha para el Desarrollo se encuentra entrabada y no ha podido ser exitosa, ya que los distintos países involucrados no han estado dispuestos a asumir obligaciones y compromisos que en los hechos les serían muy difíciles de cumplir, en atención a las múltiples presiones sectoriales a las que hemos hecho mención en el desarrollo de este estudio.

Quizás lo que más se echa de menos y consecuencialmente podría criticarse en los sistemas de solución de controversias estudiados es la falta de una reparación efectiva a los sectores productivos perjudicados con la acción u omisión que vulnere los compromisos internacionales asumidos ${ }^{59}$, más aún cuando entendemos que el principio de responsabilidad y reparación es un principio fundamental del Derecho Internacional ${ }^{60}$. El productor y/o exportador que súbitamente se vio afectado por un alza de aranceles o quien se encuentra sujeto a conductas que constituyan competencia desleal por subsidios no autorizados en el sistema multilateral de comercio, a modo de ejemplo, es quien no recibe una reparación por los numerosos daños a que puede verse expuesto, esta es una materia que -nuestro juicio- es necesario subsanar.

\footnotetext{
59 “(...) el sistema normativo de la OMC se interesa por la estimulación del cumplimiento y se despreocupa de la reparación de los daños infligidos, no contempla esta posibilidad de justicia retrospectiva correctiva, sino que opera ex nunc. La noción de Derecho internacional de restitución por equivalencia no tendría aplicación y los elementos básicos de la restitutio in integrum no se retienen de forma completa bajo el Derecho de la OMC”. Ibid., p. 193.

${ }^{60} \mathrm{La}$ Corte Permanente de Justicia Internacional en el caso Usina de Chorzow expresó: "La Corte comprueba que es un principio de derecho internacional, incluso una obligación general de derecho, que toda violación de una obligación internacional trae consigo una obligación de reparar". En: BENADAVA, Santiago, op. cit. (n. 32), p. 143.
} 


\section{REFERENCIAS BIBLIOGRÁFICAS}

Aimone Gibson, Enrique. Derecho Económico Internacional. Ediciones Universitarias de Valparaíso, Valparaíso, 1980.

Arteaga Echeverría, Ignacio. Procedimiento de solución de controversias en la Organización Mundial de Comercio. En: Gaceta Jurídica, No 261, 2002, LexisNexis, Santiago.

Baierlein Hermida, Hugo. Chile- Unión Europea ¿Cómo aprovechar el Acuerdo? Santiago, LexisNexis, 2003.

BARre, Raymond. Economía Política 2, 7a ed. (traducción de José Ignacio García Lomas). Barcelona, Editorial Ariel, 1958.

BASAldúA, Ricardo Javier. La Organización Mundial del Comercio y la regulación del Comercio Internacional. LexisNexis Argentina S.A., 2007.

BenadaVA, Santiago. Derecho Internacional Público, 6a ed. Editorial Jurídica ConoSur, Santiago, 1999.

BigGS, Gonzalo. "El mecanismo de solución de controversias en la Organización Mundial de Comercio (OMC)". En Jornadas de Derecho Internacional: 29 de noviembre a 2 de diciembre de 2004. Santiago, Organización de Estados Americanos y Sociedad Chilena de Derecho Internacional, 2005.

. "El procedimiento de solución de controversias de la OMC. La experiencia de América Latina y el Caribe”. En: Revista de la CEPAL, No 86, agosto 2005, Santiago.

BlÁzquez NaVARro, Irene. "Cumplimiento del Derecho Internacional en el sistema de solución de diferencias de la OMC". En: Revista Española de Derecho Internacional, Vol. LVIII- 2006, Núm. 1, Boletín Oficial del Estado; Madrid, 2007.

Cadena Afanador, Walter. La nueva Lex Mercatoria. La transnacionalización del Derecho. Bogotá, Centro de Investigaciones Socio Jurídicas, Facultad de Derecho, Universidad Libre de Colombia, 2004.

Cruz Miramontes, Rodolfo. Las Controversias comerciales en el marco de la Organización Mundial de Comercio (OMC). En: Anuario Hispano-Luso-Americano de Derecho Internacional, No 16, Instituto Hispano-Luso-Americano de Derecho Internacional, Madrid, 2003.

De La PeÑA, Alejandro. "Principales retos para el sistema multilateral de comercio en los próximos años" En: Foro Internacional, Volumen XLI, Número 2, Colegio de México, Ciudad de México, 2001.

Ellsworth y Clark. Comercio Internacional, $3^{\text {a }}$ edición en español. Fondo de Cultura Económica, México DF., 1978.

Espinoza Carmona, Juan Guillermo. De Doha a México. La actual ronda de negociaciones multilaterales en la OMC y la participación de los paises de América Latina y el Caribe en este debate. Santiago, Academia Diplomática de Chile Andrés Bello, 2003.

Fratalocchi y Zunino. El Comercio Internacional de Mercaderías. Su regulación en la Organización Mundial de Comercio. Buenos Aires, Osmar D. Buyatti Librería Editorial, 1997.

Gamboa Serazzi, Fernando y Fernández Undurraga, Macarena. Tratado de Derecho Internacional Público y Derecho de Integración. Santiago, LexisNexis, 2005.

Gattinoni De Mujía, María. "La aplicación judicial del Derecho Mercosur en casa uno de los Estados parte. Algunas consideraciones sobre las reformas introducidas por el Protocolo de Olivos". En: Jornadas de Derecho Internacional: 29 de noviembre a 2 de diciembre de 2004. Santiago, Organización de Estados Americanos y Sociedad Chilena de Derecho Internacional, 2005.

Greenwald, Joseph. "Solución de Controversias en la OMC". En: Foro Internacional, Volumen XLI, Número 2, Colegio de México, Ciudad de México, 2001.

Leiva Lavalle, Patricio. La Asociación Estratégica Chile- Unión Europea. Santiago, CELARE, 2003.

MAC LEAN, Roberto. Derecho de Comercio Internacional, Nuevas Tendencias. Lima, Centro de Investigación y Capacitación, Editorial ITAL Perú S.A., 1980. 
Marzorati, Osvaldo J. Derecho de los Negocios Internacionales, 2a edición actualizada y ampliada. Buenos Aires, Editorial Astrea, 1997.

MaYOrga, Roberto, MORAles, Joaquín y POlanco, Rodrigo. Inversión Extranjera. Régimen Jurídico y Solución de Controversias. LexisNexis, Santiago, 2005.

Morales BARRía, Fernando. "La responsabilidad internacional económica del Estado de Chile está íntimamente ligada al excesivo bilateralismo". En: La Revista de Derecho, Universidad Central de Chile, Año X, No 7, Santiago, julio- diciembre 2004.

MORALES, Joaquín. "Solución Internacional de controversias en materia de inversiones CIADI o UNCITRAL, ¿Cuál camino escoger?” En: Jornadas de Derecho Internacional: 29 de noviembre a 2 de diciembre de 2004. Santiago, Organización de Estados Americanos y Sociedad Chilena de Derecho Internacional, 2005.

OMC. Manual sobre sistema de solución de diferencias de la OMC. Éditions Yvon Blais, Quebec, 2004.

Piérola CASTRo, Fernando. Solución de diferencias en la Organización Mundial de Comercio. Lima, Instituto de Estudios Internacionales, Pontifica Universidad Católica del Perú, Editorial DESA, 2002.

REY CARO, Ernesto. "Los mecanismos y procedimientos para la solución de controversias en el MERCOSUR. Antecedentes, realidad y perspectivas". En: PUEYO, J. y REY CARO, E. (Coords). MERCOSUR: Nuevos ámbitos y perspectivas en el desarrollo del proceso de integración. Buenos Aires, Editorial Ciudad Argentina, 2000.

Ruiz Díaz Labrano, Roberto. MERCOSUR. Integración y Derecho. Buenos Aires, Editorial Ciudad Argentina, 1998.

Saldaña PéRez, Juan Manuel. Comercio internacional. Régimen Jurídico Económico. Editorial Porrúa, México DF, 2008.

SALINAS BURGOS, Hernán. "Solución de controversias en acuerdos sobre libre comercio. Derecho aplicable y su relación con el sistema de la Organización Mundial de Comercio". En: Jornadas de Derecho Internacional: 29 de noviembre a 2 de diciembre de 2004. Santiago, Organización de Estados Americanos y Sociedad Chilena de Derecho Internacional, 2005.

Sierralta Ríos, Aníbal. Contratos de Comercio Internacional, $4^{\mathrm{a}}$ ed. Lima, Pontificia Universidad Católica del Perú, Fondo Editorial, 2004.

TAMAmes, Ramón. HUerTA, Begoña. Estructura Económica Internacional, 19a ed. Madrid, Alianza Editorial, 1999.

WitKer, Jorge. Solución de Controversias Comerciales en el Tratado de Libre Comercio Chile - Estados Unidos. Santiago, LexisNexis, 2005.

\section{ARTÍCULOS DE DIARIOS}

"FORESTALES de EE.UU. presionan para seguir recibiendo subsidios". El Mercurio, Santiago, Chile, 2 de julio, 2009. B-5.

"Iansa Defiende Renegociar el Arancel Consolidado ante OMC", <en línea> El Mercurio en internet. 6 de noviembre, 2000. Disponible en la Worl Wide Web: <http://diario.elmercurio.cl/detalle/ index.asp?id=\%7Bbf77bde4-a3e4-421d-b56b-212ba9ae9ae1\%7D>;"El azúcar, otro punto de discordia en el MERCOSUR", <en línea>

La Nación en internet. 21 de abril, 1997. <http://www.lanacion.com.ar/nota.asp?nota_id=67462>; EDITORIAL. "El proteccionismo al acecho", <en línea> La Nación en internet. 2 de marzo, 2009. <http:// www.lanacion.com.ar/nota.asp?nota_id=1104531> 